\title{
Final Project Report Staff Exchange with Finnigan Corporation
}

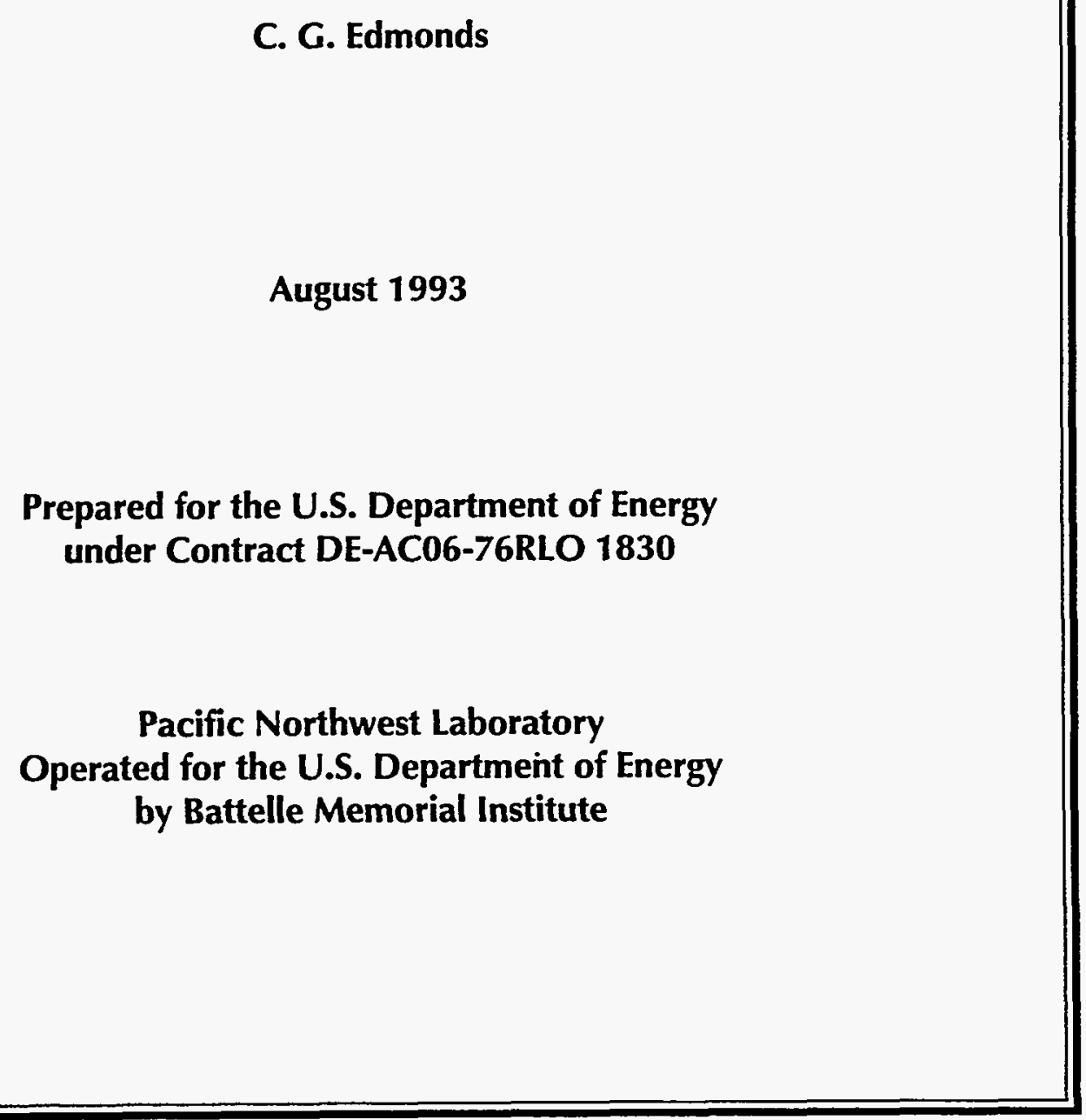




\title{
DISCLAIMER
}

This report was prepared as an account of work sponsored by an agency of the United States Government. Neither the United States Government nor any agency thereof, nor Battelle Memorial Institute, nor any of their employees, makes any warranty, expressed or implied, or assumes any legal liability or responsibility for the accuracy, completeness, or usefulness of any information, apparatus, product, or process disclosed, or represents that its use would not infringe privately owned rights. Reference herein to any specific commercial product, process, or service by trade name, trademark, manufacturer, or otherwise does not necessarily constitute or imply its endorsement, recommendation, or favoring by the United States Government or any agency thereof, or Battelle Memorial Institute. The views and opinions of authors expressed herein do not necessarily state or reflect those of the United States Government or any agency thereof.

\author{
PACIFIC NORTHWEST LABORATORY \\ operated by \\ BATTELLE MEMORIAL INSTITUTE \\ for the . \\ UNITED STATES DEPARTMENT OF ENERGY \\ under Contract DE-AC06-76RLO 1830
}




\section{DISCLAIMER}

Portions of this document may be illegible in electronic image products. Images are produced from the best available original document. 
PNL-8641

UC-900

\title{
Final Project Report Staff Exchange with Finnigan Corporation
}

\author{
C. G. Edmonds
}

August 1993

Prepared for

the U.S. Department of Energy

under Contract DE-AC06-76RLO 1830

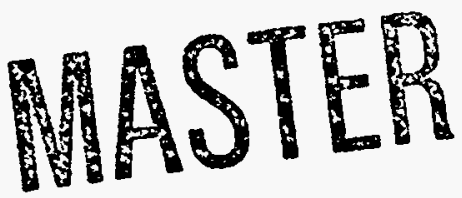

Pacific Northwest Laboratory

Richland, Washington 99352 


\section{Final Project Report Staff Exchange with Finnigan Corporation}

\section{Purpose/Objective}

The objective of the exchange between Pacific Northwest Laboratory (PNL) ${ }^{(a)}$ and Finnigan Corporation is a transfer of expertise and technology for the design and operation of efficient and sensitive atmospheric pressure/vacuum electrospray ionization (ESI) sources. The development of such ion sources will permit wider application of mass spectrometry instrumentation in applied studies in a variety of disciplines including clinical, forensic, biochemical, biotechnical, and environmental studies where sensitivity is a paramount concern. (See the appendix for additional information.)

\section{Summary of Activities Performed}

Two meetings were held between representatives of Finnigan Corporation (led by Dr. Ian Jardine, Director for Marketing, Finnigan Corporation) and PNL staff members. During these meetings, Finnigan and PNL staff surveyed the existing technology for atmosphere/vacuum interface of mass spectrometry to ESI. The representatives from Finnigan viewed demonstrations of recent developments that increased efficiency and sensitivity for ESI mass spectrometry. During these meetings, knowledge and expertise were shared in the development of instrumentation, methods, and applications of ESI mass spectrometry with particular emphasis on current and planned Finnigan instrumentation. With the objective of more effective and competitive products for Finnigan Corporation, concepts for a Cooperative Research and Development Agreement (CRADA) were directed toward the development and commercialization of advanced high efficiency and sensitivity ESI technology. A detailed proposal and work plan for the cooperative project was developed.

\section{Significant Accomplishments}

A collaborative team was established focusing on the applications and markets defined by the problems involved in the development of advanced high-sensitivity methodologies and instrumentation incorporating the ESI technology. This was the initial step in building a long-term collaborative relationship between PNL and Finnigan. A proposal for a CRADA was developed which when implemented will enhance the competitive position of this important U.S. player in the international analytical instrumentation market.

(a) Pacific Northwest Laboratory is operated for the U.S. Department of Energy by Battelle Memorial Institute. 


\section{Significant Problems}

Due to the relatively limited resources approved for this activity $(\$ 20,000)$, it was determined not to undertake of all the originally proposed exchange of technical and scientific staff for laboratory activities and development work at Finnigan Corporation in San Jose, California, and at PNL in Richland, Washington. Instead, the work focused on the preparation of the follow-on document making every effort to fully define the range of mutual interests and complementary capabilities. The production of a well-integrated CRADA proposal, reflecting the full consensus in these matters, is the result.

\section{Industry Benefits Realized}

During the meetings with Finnigan personnel, important consensus was established on the useful directions for joint work on the development of advanced high efficiency and sensitivity ESI technology. This consensus was outlined for expansion into a draft of the CRADA. In subsequent exchanges, a mutually satisfactory document in the form of a detailed Field Work Proposal was created. It is planned that the essence of this proposal will be submitted to the Office of Energy Research, Laboratory Technology Transfer for evaluation and approval.

\section{Recommended Follow-on Work}

The array of proposed laboratory and demonstration exchanges should be completed. The momentum generated by these activities will flow logically and practically toward the full realization of the goals outlined in the CRADA proposal, which outlines a unique combined theoretical and practical approach to the development of high efficiency and sensitivity ESI source technology. That technology is well suited to present mass spectrometry instrumentation, and the instrumentation planned for development and introduction by Finnigan Corporation.

\section{Potential Benefits from Pursuing Follow-on Work}

The objective of this project is to develop an advanced high-sensitivity ESI source for mass spectrometry. The recent development of ESI permits the transfer of ions from solution to the gas phase with high efficiency. This is a new capability which all mass spectrometer manufacturers are adapting for biological and pharmaceutical research, clinical assays, environmental testing and monitoring, and many other areas where sensitivity and specificity are primary concerns. The major limitation of this approach is the fact that current ESI sources provide signal intensities which are often too small. ESI ions are initially formed at atmospheric pressure, and in the process of creating a focused ion beam appropriate for mass spectrometry, more than $99.9 \%$ are lost. This collaborative research with Finnigan MAT, the only U.S. manufacturer of research-grade mass spectrometers, will greatly increase the U.S. competitive position in the commercialization of advanced analytical instrumentation. The approach will utilize advanced fluid dynamics computational capabilities, experimental studies of ion formation and ion optics, and build upon expertise and prototype PNL ESI source designs, with the aim of developing ESI sources optimized for ion trap mass spectrometers. 


\section{Appendix}

High Sensitivity Electrospray Ion Source Development Field Work Proposal 
U. S. DEPARTMENT OF ENERGY

Richland Field office

FIELD WORK PROPOSAL

\begin{tabular}{|c|c|c|c|c|c|}
\hline & $\begin{array}{l}\text { 1A. Contractor Number } \\
20143\end{array}$ & 2. Revision Number & \multicolumn{3}{|c|}{$\begin{array}{l}\text { 3. Date Prepared } \\
\text { January 15, } 1993\end{array}$} \\
\hline 4. & $\begin{array}{l}\text { Package Title } \\
\text { High Sensitivity Electrospray Ion Source } \\
\text { Development }\end{array}$ & $\begin{array}{l}\text { Budget and Reporting Code } \\
\text { KT }-04-00-00-0\end{array}$ & & & \\
\hline 6. & $\begin{array}{l}\text { Work Proposal Term } \\
\text { Begin } 10 / 1 / 92\end{array}$ & $\begin{array}{l}\text { 7. Is this Work Package Inclu } \\
\text { Yes }\end{array}$ & ed in & the Inst & utional Plan? \\
\hline B. & $\begin{array}{l}\text { Headquarters/Field Program Manager } \\
\text { (Name: Last, First, Middle Initial) (FTS No.) } \\
\text { Claftin, Alan } 896-3560 \\
\text { Zerega, Anne Marie } 896-3560\end{array}$ & Headquarters Organization & 10. & DOE-HQ O & anization Cod \\
\hline 11. & $\begin{array}{l}\text { Field Office Work Proposal Manager } \\
\text { (Name: Last, First, Middle Initial) (FTS No.) } \\
\text { McClure, Gail 444-0343 }\end{array}$ & $\begin{array}{l}\text { 12. Field office } \\
\text { Richland Field } \\
\text { Office }\end{array}$ & 13. & DOE Orga & zation Code \\
\hline 14. & $\begin{array}{l}\text { Contractor Work Proposal Manager and Principal Investigator } \\
\text { (Name: Last. First, Middle Initial) (FTS No.) } \\
\text { Smith, Richard D. } 444-0723 \\
\text { Udseth, Harold R. } 444-3698\end{array}$ & $\begin{array}{l}\text { Battelle Memorial I } \\
\text { Pacific Northwest L }\end{array}$ & & $\begin{array}{l}\text { tute } \\
\text { atory }\end{array}$ & 16. Code \\
\hline
\end{tabular}

17. Work Proposal Description (Approach, Anticipated Benefit, in 200 Words or Less)

The objective of this project is to develop an advanced high sensitivity electrospray ionization (ESI) source for mass spectrometry. The recent development of ESI permits the transfer of ions from solution to the gas phase with high efficiency. This is a new capability which all mass spectrometer manufacturers are adapting for biological and pharmaceutical research, clinical assays, environmental testing and monitoring, and many other areas where sensitivity and specificity are primary concerns. The major limitation is the fact that current ESI sources provide signal intensities which are often too smal1. While ESI ions are initially formed at atmospheric pressure, and in the process of creating a focused ion beam appropriate for mass spectrometry, more than $99.9 \%$ are 1ost. This collaborative research with Finnigan MAT, the only U.S. manufacturer of research grade mass spectrometers, will greatly increase the U.S. competitive position in the commercialization of advanced analytical instrumentation. The approach will utilize advanced fluid dynamics computational capabilities, experimental studies of ion formation and ion optics, and build upon expertise and prototype PNL ESI source designs, with the aim of developing ESI sources optimized for ion trap mass spectrometers. The improved performance will provide secondary benefits due to the important range of application. Key Words: Analysis, Instrumentation, Mass Spectrometry, Electrospray Ionization 
UORK PROPOSAL. REQUIREMENTS FOR OPERATING/EQUIPHENT OBLIGATIONS AND COSTS

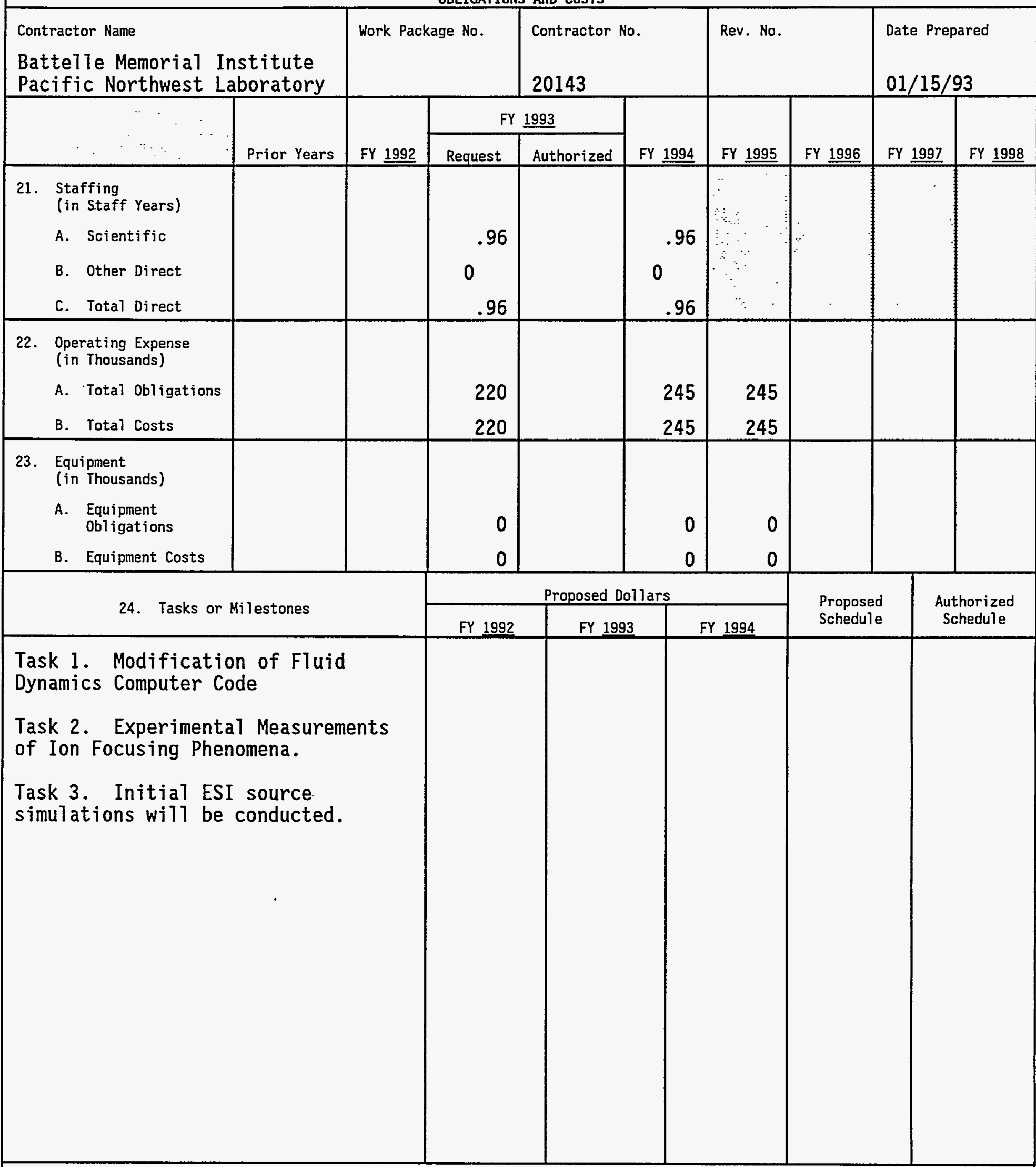

25. Reporting Requirements (Description) Annual reports and peer-reviewed publications. 
Field Uork Proposal (Optional Continuation Sheet)

\begin{tabular}{|c|c|c|c|c|}
\hline $\begin{array}{l}\text { Contractor Hame } \\
\text { Battelle Memorial Institute } \\
\text { Pacific Northwest Laboratory }\end{array}$ & Nork Package Ho. & $\begin{array}{l}\text { Contractor Ho. } \\
20143\end{array}$ & Revision Ho. & $\begin{array}{l}\text { Date Prepared } \\
01 / 15 / 93\end{array}$ \\
\hline
\end{tabular}

\section{A. Purpose}

The purpose of this project is to improve the understanding of the transport and focusing of charged particles formed at atmospheric pressure and through the interface into the high vacuum region of a mass spectrometer. The project will build upon PNL's research experience, technologies and unique research capabilities with the aim of developing and commercialization of an improved electrospray ion source in collaboration with Finnigan MAT. The role of PNL in this collaboration will be to develop fluid dynamics computatorial models to be used in conjunction with experimental studies of ion focusing phenomena at atmospheric pressure and during the transition to high vacuum conditions to improve ion transmission. This project will provide the essential foundation for Finnigan MAT to implement an advanced electrospray ionization source on its various mass spectrometer product 1 ines, which is likely to provide a basis for much broader application of mass spectrometry to environmental testing, monitoring, clinical assays, drug testing, etc., as well as a broad range of research applications.

The proposed project is a lateral extension of PNL research performed for the ER Office of Health and Environmental Research which has been developing advanced methods for chemical and biochemical analysis based upon the combination of capillary electrophoresis with electrospray ionization-mass spectrometry. While not directly related to current project goals, recent results have shown that current ESI sources are inefficient due to large ion losses during transport from the atmospheric pressure region, where ions are formed, into the high vacuum region required for mass spectrometer operation. The low overall efficiency of this process, about $10^{-4}$ to $10^{-5}$, currently precludes a broad range of potential applications which, if viable, would greatly increase the market for ESI-MS instrumentation. The aim of this CRADA is to allow PNL to conduct the research necessary to better understand ion transport from atmosphere to vacuum. This will allow Finnigan MAT to develop much more effective ESI sources for its line of commercial mass spectrometers.

Although the proposed project is specifically aimed at the development of advanced analytical instrumentation based upon electrospray ionization sources, the information developed in this project is relevant to other high pressure ion sources for mass spectrometers, as well as other potential types of analytical instrumentation based upon ion transport (e.g., thermo ionization and electron capture detectors), which also constitute commercial markets. In addition, charged particle transport in gases is broadly relevant in atmospheric processes, and in some isotopic separation concepts.

of particular interest is the analytical capability which would be provided by combining the high resolution separations feasible with capillary electrophoresis with the capability of ESI-MS to detect and characterize complex chemical and biochemical species (e.g., proteins). The CE-MS combination is currentiy of marginal utility for many applications due to sensitivity constraints of ESI-MS. A successful research effort under this project would dramatically enhance the CE-MS combination, opening a host of applications in complex mixture analysis, biochemical characterization, etc., each of which could give rise to broad, new commercial markets.

Finnigan MAT (San Jose, CA) plans a major commitment of resources and personnel to this collaborative research agreement (\$700K, in-house). The concurrent research effort at Finnigan MAT will involve developing advanced ESI sources for its line of mass spectrometers, 
with emphasis on the ion trap mass spectrometer, widely viewed as the basis for most future mass spectrometers. Fundamental information from computational and experimental studies at PNL will materially assist them in advanced ESI source designs that are optimized for specific Finnigan MAT products. The extensive background and capabilities provided by PNL, in addition to two patents awarded to PNL for ESI sources, the combination of CE-MS based upon this source was honored by an R\&D 100 award in 1988, are expected to greatly accelerate the commercialization of advanced ESI source technology, giving Finnigan MAT a competitive advantage.

\section{B. Background}

Over the last four years, there has been an explosive increase in the interest in electrospray ionization (ESI) techniques for mass spectrometry. At the annual meeting of the American Socjety for Mass Spectrometry in 1988, ESI was included in only seven posters. At the 1992 meeting, there were over 200! Mass Spectrometry, in general, is probably the most broadly applicable analytical technique. It finds broad application in chemical and biological research, environmental testing, process monitoring, atmospheric monitoring, drug testing, etc. The greatest barriers to broader use are related to cost and limitations in present day ion source applicability and sensitivity. In the former case, costs continue to drop and this trend should continue as advanced ion trap mass spectrometers are more widely implemented. Finnigan MAT, which developed the modern quadrupole ion trap mass spectrometer, has developed product Tines based on specific applications. However, limitations in ion source technology continue to hinder market growth into areas which require high sensitivity applications (such as clinical assays). Improved ESI ion source technology would provide the basis for growth into such arenas.

Due primarily to its development of the quadrupole ion trap mass spectrometer, Finnigan MAT retains a leading role among the major manufacturers of mass spectrometers. In the manufacture of research mass spectrometers, Finnigan MAT is the most competitive U.S. based business. Electrospray ionization for analysis was pioneered by Malcolm Dole in the late 1960 's. Subsequent work by John Fenn and coworkers at Yale and research at PNL played a dominant role in the discovery and early implementation of ESI sources on mass spectrometers in the late $1980^{\prime} \mathrm{s}$. However, due to its significance for chemical analysis, and the size of potential markets, all major manufacturers quickly offered ESI sources. As a result, foreign manufacturers already have a competitive advantage in this growing market that was pioneered and developed in the United States.

The proposed collaborative project between PNL and Finnigan MAT would provide the bas is for a competitive edge to U.S. industry by providing a greatly improved ESI source technology. In particular the combination of improved ESI source technology with quadrupole ion trap mass spectrometers should provide a foundation for highly competitive future products. The major elements of this project will involve the use of computational fluid dynamics methods to evaluate charged particle trajectories over a range of densities in order to improve ion transport and focusing through the ESI-MS interface. PNL's experience with ESI began in 1984, and support through DOE's Office of Health and Environmental Research has continued since 1986. PNL invented the combination of capillary electrophoresis with ESI-MS (i.e., CE-MS), and has been responsible for a number of significant improvements to ESI sources as well as the development of techniques related to its application for the characterization of large biochemical molecules. PNL has received two patents for ESI 
technology and has more than fifty publications in peer-reviewed scientific literature involving its applications. PNL's unique capabilities, experience, and expertise make it ideally suited for its participation in the proposed CRADA with Finnigan MAT, providing a high probability of successful pay-off in terms of enhanced competitiveness of U.S. industry in analytical instrumentation. The development of such improved analytical instrumentation is also directly relevant to DOE's waste site interests. Analytical measurements used for monitoring, remediation, and clean-up efforts are critically important at the various DOE sites.

\section{Electrospray Ionization}

Below, we outline the development of electrospray ionization and our current level of understanding of the experimental factors that are currently known to 1 imit its performance. Included in this analysis are preliminary studies which we believe indicate that much more efficient ESI source technology is possible.

Electrospray ionization-mass spectrometry (ESI-MS) had its origins in research that long preceded the current flurry of activity. The study of the electrospray phenomena extends back perhaps over two and one-haif centuries to the work of Bose (1), and certainly to that of Zeleny early in this century (2). The seminal research into the use of electrospray as an jonization method for macromolecules was due to Malcom Dole and coworkers $(3,4)$, who, more than twenty years ago performed extensive studies into the electrospray process, and defined many of the important experimental parameters. The purpose of Dole's studies was to use ESI to produce gas phase macro-ions. In 1984, ESI combined with mass spectrometry was reported, essentially simultaneous7y, by both Yamashita and Fenn (5) and Aleksandrov et al. $(6,7)$. Fenn and coworkers also demonstrated ESI-MS in the negative ion mode (8), building upon the original negative ion work by Dole and coworkers. Using a magnetic sector instrument, the Soviet researchers independently demonstrated the on-line combination with liquid chromatography in 1984 (7), and over the next few years applied ESI-MS to o7igosaccharides (9), and intact polypeptides up to $M_{r} 1500$ (10), and developed chemical digestion-based methods for their sequence determination (11).

Of particular importance to ESI analysis of macromolecules is the phenomenon of multiple charging. The multiple charging of Tysozyme by ESI was reported by Dote on the basis of ion mobility measurements, but difficulties in the interpretation led them to suggest a charge state of only 3t, substantially lower than shown by subsequent MS studies. In 1985, both Fenn and coworkers $(12)$ and Aleksandrov et a7. $(9,10)$ reported dominant contributions for doubly charged ions for polypeptides such as bradykinin ( $\left.M_{1} 1060\right)$ and gramicidin $S\left(M_{r} 1141\right)$. Aleksandrov et al. Tater reported the analysis of a polypeptide of $M_{3} 3492$ that produced intense doubly and triply protonated molecular ions (13). Most significant, however, was the report by Fenn and coworkers of polyethylene glycols of average molecular weights up to 17,500 with as many as 23 charges (due to associated sodium ions) (14). Since the higher molecular weight polyethylene glycol samples had relatively broad molecular weight distributions, only unresolved "humps" of ions from $\mathrm{m} / \mathrm{z}-550$ to $>1400$ were observed for these materials. Further studies required a polymer of better defined molecular weight. The next step involved the study of such naturally occurring polymers: proteins. In 1988, Fenn and coworkers (15) first reported ESI-MS spectra of intact multiply protonated molecules of proteins up to $M_{\text {40 }} 40,000$, having as many as 45 positive charges. We reported our first electrospray work on proteins also in $1988(16,17)$ as did Covey et al (18). 
U. S. DEPARTHENT OF EHERGY

Richland Field office

Field Hork Proposal (Optional Continuation Sheet)

Page 4 of 15

Contractor Hame

Nork Package Ho.

Contractor No.

Revision Ho. 20143

Date Prepared

Battelle Memorial Institute

Pacific Northwest Laboratory

practice of ESI-MS has grown impressively. One obvious reason for this is the speed with which commercial instrumentation became available, and particularly the ease to retrofit existing quadrupole mass spectrometers for ESI-MS. ESI has established clear advantages for analysis of liquid samples and solutions, particularly the effluents from microscale or "nanoscale" capillary separation methods. In addition, tandem mass spectrometry has been used for dissociation studies of multiply charged biomolecules produced by ESI, allowing much greater dissociation efficiencies than for singly charged molecular ions (19). If further developed with sufficient sensitivity, the combination of these capabilities constitutes technology capable of profoundly affecting the practice of mass spectrometry and allowing its extension to broad new areas of application in health care and environmental clean up. Continued development of such advanced analytical tools will require an improved understanding of ion transmission and sensitivity. It is precisely these issues at which this project is aimed.

The importance of the sensitivity issue cannot be overstated; improved sensitivity will provide a much broader application of mass spectrometry. These applications would extend across broad commercial sectors, the health care industry, and especially environmental clean-up for which a major fraction of the costs generally involve chemical analysis. As noted in a recent review (20), "These pressing [sensitivity] problems provide the driving force and justification for continued technical innovation which will permit their solution with future generations of state-of-the-art research grade and commercial instrumentation. Consider one case in point: The disparity between the optimal performance characteristics of capillary zone electrophoresis and the operational sensitivity of virtually all presently available mass spectrometric instrumentation. The desirability of a marriage [i.e., CE-MS] which would preserve the unprecedented resolution of separations with accurate mass spectral analysis is irrefutable." The mass spectrometer source, including the interface, is the central concern of this proposal. The ideal ion source/interface sends to the mass analyzer at high vacuum an intense ion beam with current generally in the $10 \mathrm{nAmp}$ to $1 \mu$ Amp range, depending upon the ionization technique, that is well collimated and nearly monoenergetic. These ions must be molecular ions, or structurally related fragments of the molecule. The ion currents produced by ESI are generally 0.1 to $0.5 \mu \mathrm{Amp}$. This is an adequate current, however it is produced a atmospheric pressure, and the usable fraction of this current (i.e. the part that can be successfully mass analyzed and detected) is typically between $10^{-12}$ and $5 \times 10^{-11}$ Amp. This disparity of 104 to 105 reduces the ESI currents detected to a Tevel where dynamic range is greatly constrained and statistical limitations intrude. Below we discuss the current situation and design of ESI sources and interfaces, and review the development to date.

The following discussion is divided into two parts based upon the functional components of the ESI-MS instrumentation. These are (A) the electrospray source, or "tip", where electrostatic nebulization of the liquid stream occurs, and (B) the atmosphere/vacuum interface where the droplets and resulting ions are desolvated and transferred from near atmospheric pressure to the vacuum environment of the mass spectrometer.

\section{The Electrospray Source}

The ESI "source" may be simply a metal capillary (e.g., stainless steel hypodermic needle) at elevated voltage relative to a counter electrode having an orifice where ions and/or droplets enter the mass spectrometer entrained in a flow of gas. In general, a 1 to 


\begin{tabular}{l|l} 
Contractor No. & Revision No. \\
20143 &
\end{tabular}

$20 \mu \mathrm{T} / \mathrm{min}$ flow of solution, generated by infusion syringes, separation devices, or other liquid sources, moves through the capillary to its terminus. When a high gas flow over the ESI capillary is added to assist the nebulization, flow rates up to $-100 \mu \mathrm{L} / \mathrm{min} \mathrm{can}$ be accomodated, making the method more amenable for interfacing with liquid chromatography at flow rates accessible with packed columns.

Interest at PNL in coupling high resolution CE separation methods with ESI-MS led to the development of the liquid sheath electrospray source (21). This ESI source has been used for most work in our laboratory due to the flexibility it provides in sample solvent selection. In one version of this source, an organic liquid sheath (typically pure methanol or acetonitrile, but frequently augmented by small proportions of acetic acjd, water and/or other reagents), flows in the annular space between an approximately $200 \mu \mathrm{m} 0 . d$. fused silica capillary, which delivers analyte solution to the ion source, and a slightly larger diameter outer capillary. In this arrangement, the inner fused silica capillary protrudes approximately $0.2 \mathrm{~mm}$. For positive ion ESI, a voltage of $+4 \mathrm{kV}$ to $+6 \mathrm{kV}$ is applied indirectly to the sheath liquid via the outer metal capillary. For experiments in which sample solution is directly infused to the ESI source, syringe pumps deliver controlled flows of analyte and sheath 1 iquids at rates of 0.1 to $1 \mu \mathrm{L} / \mathrm{min}$ and 2 to $5 \mu \mathrm{L} / \mathrm{min}$, respectively, through lengths of fused silica capillary.

The ESI source requires production of a high electric field at the capillary tip which leads to the formation of highly charged liquid droplets. The electric field causes charge accumulation on the liquid surface at the capillary terminus and disrupts the liquid surface. Thus the liquid flow rate, resistivity, and surface tension are important factors in the formation of a stable electrospray (22). Reasonable agreement with experimental results have been obtained for the following relationship:

$$
V_{0} \propto\left(T_{s} \cdot \tau\right)^{0.5} \text { en }(4 h / r)
$$

where $V_{0}$ is the electrospray onset voltage, $T_{s}$ is the surface tension, $r$ is the capillary radius, and $h$ is the capillary tip to a planar counter-electrode distance (23). Liquids with surface tensions $\geq 0.05 \mathrm{~N} / \mathrm{m}$ cannot be electrosprayed in air with a 275 m diameter capillary without a corona discharge. However, it appears that sharp, smaller diameter capillaries allow electrospraying in air over a limited voltage range (24). Because droplet size decreases with increasing solution conductivity, decreased liquid flow rates are required to electrospray increasingly conductive liquids. Higher flow rates of more highly conductive liquids lead to unstabie performance ("spitting") and larger droplet sizes. The dependence of ESI ion current (I) upon solution conductivity (s) is relatively weak (Ias ${ }^{0.22}$ ) (25). ESI currents for a typical water/methanol/5\% acetic acid solution are in the range of 0.1 to 0.5 $\mu \mathrm{A}$.

At a short distance from the ESI source, the nebulized liquid has a nearly monodisperse droplet diameter on the order of $1 \mu \mathrm{m}(22,26)$. Increased liquid flow rates result in 1 arger droplets (27), and the total electrospray ion current increases only slightly. Increased electrolyte concentration causes a decrease in the average droplet size. The use of higher voltages does not substantially increase the ion current until the onset of a corona discharge. 
There is evidence that heating of the droplets is useful for manipulating the electrospray process. For example, results indicate that slight heating allows aqueous solutions to be readily electrosprayed (28), presumably due to decreased viscosity and surface tension. Both thermally assisted (29) and pneumatically assisted electrosprays allow higher liquid flow rates, but decrease the extent of droplet charging. The reduced droplet charging may also be related to the lower average charge state observed for multiply charged ions, and necessarily results in a lower ionization efficiency for singly charged ions. The maximum extent of charging results from the electrospray process, and any method aimed at "assisting" ESI is expected to decrease charging (30).

\section{Atmospheric/Nacuum Interface.}

The formation of macromolecular ions requires conditions promoting solvent evaporation from the initial droplet population. This can be accomplished at near-atmospheric pressures by a counter current flow of dry gas at moderate temperatures $(80 \mathrm{C})$, by heating during transport through the interface, and by (particularly in the case of ion trapping methods) energetic collisions at relatively low pressure. In all cases, droplets shrink to the point where repulsive Coulombic forces approach the level of droplet cohesive forces (e.g., surface tension), the so called Rayleigh 1 imit, whereupon they explode. The maximum droplet charge for stability is proportional to $\mathrm{d}^{3 / 2}$ ( $\mathrm{d}=$ droplet diameter) and for 7 arge $(>1 \mu \mathrm{m})$ droplets, there is no doubt that the Rayleigh limit applies. Such droplets have been observed to form a protrusion from which smaller droplets are emitted, typically shedding more than $10 \%$ of their charge, and about one order of magnitude less mass (31). It has been postulated that droplets in an ESI source undergo several such fission processes, yielding smaller and smaller droplets until the electric field at the droplet surface is sufficient for ion evaporation (32-34). On the basis of residual particle measurements, an initial droplet size of $-1 \mu \mathrm{m}$ has been deduced. There is also evidence of second generation droplets in the 0.01 to $0.1 \mu \mathrm{m}$ size range (26). Mass spectra from the electrospray process represent the end product and are not representative of the actual species present at atmospheric pressure.

The Tow efficiency of ion detection in ESI arises from a number of factors. First at atmospheric pressure, ion motion is governed largely by the bath gas, and local electric fields (and to a much lesser extent, magnetic fields). The major constraint however, is a result of ion-ion repulsive forces, which give rise to a "space charge effect." The initial electrospray plume originates from a point at the tip of the "Taylor cone" and spreads to approximately $1 \mathrm{~cm}$ diameter by the time ions have drifted for about $2 \mathrm{msec}$ in the electric field of the ESI source. The $-2 \mathrm{msec}$ period is the approximate time required for droplets and ions to migrate the 1-2 cm distance from the electrospray "tip" to the mass spectrometers sampling orifice (as determined in ion mobility analysis studies at PNL). Constraints on the practical pumping restrict the size of an orifice compatible for direct introduction to a mass spectrometer to approximately $1 \mathrm{~mm}$. In addition to well-understood discrimination effects relevant to all ion sources, the atmospheric pressure ion source presents unique differences. Ions of different mass (not $\mathrm{m} / \mathrm{z}$ ) acquire different translational energies in the gas expansion from atmospheric pressure. Indeed, certain lens potentials can almost completely discriminate against lower energy (mass) species, as in retarding potential analysis. Other uncertainties arise due to the unknown extent of solvation at atmospheric pressure. The importance of this factor has not yet been widely recognized. However, preliminary work at PNL has clearly demonstrated the importance of effective desolvation for ion detection. In the absence of effective desolvation, it is possible to have Targe ion 


\begin{tabular}{|c|c|c|c|c|}
\hline $\begin{array}{l}\text { Contractor Name } \\
\text { Battelle Memorial Institute } \\
\text { Pacific Northwest Laboratory }\end{array}$ & Work Package Ho. & $\begin{array}{l}\text { Contractor Ho. } \\
20143\end{array}$ & Revision No. & $\begin{array}{l}\text { Date Prepared } \\
01 / 15 / 93\end{array}$ \\
\hline
\end{tabular}

currents that do not yield useful mass spectra since the ions are solvated and effectively spread across (or beyond) the mass spectrum.

Several different strategies have been used in existing atmospheric/vacuum interfaces. Ion sampling in ESI can use orifices (as simple as holes in plates), capillaries, and likely other methods in the future. Ion desolvation can be conducted prior to sampling (in which case it is only partially effective), during transport through a capillary, or in the MS interface. Many ESI sources use an atmospheric pressure counter-current flow of dry $\mathrm{N}_{2}$ which serves to exclude large droplets and particles and aid desolvation. The counter-current flow of bath gas sweeps away high $\mathrm{m} / \mathrm{z}$ residual particles and solvent vapor from the mass spectrometer inlet. As the ions pass through the orifice into the vacuum, further desolvation is accomplished by collisions as the ions are accelerated into the mass spectrometer.

A simple design (available as a commercial instrument from Sciex, Thornhill, Ontario, Canada) utilizes a 100 - to $130-\mu \mathrm{m}$ orifice to a vacuum region maintained by a single stage of high-speed cryo-pumping. The strategy most often employed to date has been to use differentially pumped vacuum systems, where the gas pressure may be dropped in several stages. This approach has allowed the use of orifices as 7 arge as $1 \mathrm{~mm}$ in our laboratory. With such an approach, as much as several percent of the total ESI current can enter the first vacuum stage. Unfortunately, at the pressure in this stage molecular decay can still be appreciable, and a large dispersion of the ion current occurs. The net result is the overa11 efficiency is reduced to $-10^{-4}$ (at best).

Alternatively, a differentially pumped capillary inlet-skimmer interface was developed by Fenn and co-workers (30). Some fraction of ions are entrained in the gas flow entering a glass capillary (metalized at both ends to establish well-defined electric fields). Ions can be transmitted through capillaries with efficiency. Ions swept by the gas flow through the capillary emerge as a component of a free jet expansion in the first differentiallypumped stage. Some fraction of the ions is then transmitted through a skimmer and ion optics into the mass spectrometer.

An alternative approach to droplet desolvation at atmospheric pressure involves heating during droplet transport through a heated metal (35) or glass capillary $(30,36)$. With such methods a curtain or counter-current gas flow is not needed, and the electrospray source is positioned closer to the sampling capillary orifice (typically. 0.3 to $1.0 \mathrm{~cm}$ ). The charged droplets are efficiently swept into the heated capillary, where thermal conditions provide effective ion desolvation. This approach is generally augmented by a capillary-skimmer voltage gradient (1argely to prevent condensation upon expansion). Advantages of the heated capillary are the ease with which it can be adapted to different MS configurations, potentially higher transport efficiency (which arises from the enhanced proximity to the electrospray "tip"), and the ability to heat ions for desolvation in a manner not highly dependent upon $\mathrm{m} / \mathrm{z}$. The application of similar methods for thermally induced dissociation has recently been developed at PNL (37).

As mentioned earlier, ion desolvation is crucial to the successful development of more sensitive ESI sources. Hithout effective desolvation, any current produced by the source is useless. The development of advanced ESI sources must not only focus much large ion currents into the MS, but assure that the ions produced are fully desolvated. The best approach to 
desolvation is likely to be determined by the particular mass spectrometer design. One of the aims of this project is to provide a basis for not only optimizing ESI currents, but to also optimize ion formation and desolvation processes, vital to overall success.

\section{Advanced ESI Source Development}

Finnigan MAT has identified ESI sources as being a vital component of its future mass spectrometers, and already. offers ESI interfaces for most of its instruments. Their competitive position against international competition will depend upon the success in developing improved ESI sources and the successfut matching of these sources with their product line, in particular the quadrupole ion trap mass spectrometer. Thus, Finnigan MAT has agreed to participate in a collaborative project with PNL aimed at the study of ion transport and desolvation phenomena, and the design of advanced high sensitivity ESI sources. Finnigan MAT will dedicate a substantial in-house research effort in this collaboration, which will use the information obtained by PNL to develop ESI ion sources optimized for specific mass spectrometer designs. The information obtained in this study will also have broader impact, likely benefiting all instrumentation based upon high pressure ion sources. other efforts at Finnigan MAT, not directly included in this collaborative project, would then develop applications, and instrumentation suited for specific market segments. The collaborative project will build upon basic research results obtained at PNL related to the use of electric and magnetic fields, hydrodynamic forces, and ion formation/desolvation phenomena relevant to ESI.

\section{References}

1. Bose, G. M. Recherches sur le cause et sur la véritable théorie de l'électricité, Wittenberg, 1745.

2. Zeleny, J. J. Phys. Rev. 1917, 10, 1-6.

3. Dole, M.; Mack, L. L.; Hines, R. L.; Mobley, R. C.; Ferguson, L. D.; Alice, M. B. J. Chem. Phys. 1968, 49, 2240-2249.

4. Mack, L. L.; Kralik, P.; Rheude, A.; Dole, H. J. Chem. Phys. 1970, 52, 4977-4986.

5. Yamashita, M.; Fenn, J. B. J. Phys. Chem. 1984, 88, 4451-4459.

6. Aleksandrov, M. L.; Gal1, L. N.; Krasnov, V. N.; Nikolaev, V. I.; Pavlenko, V. A.; Shkurov, V. A. Dok7. Akad. Nauk SSSR 1984, 277, 379-383

7. Aleksandrov, M. L.; Gall, L. N.; Krasnov, V. N.; Nikolaev, V. I.; Pavlenko, V. A.; Shkurov, V. A.; Baram, G. I.; Gracher, M. A.; Knorre, V. D.; Kusner, Y. S. Bioorg. Kim $1984,10,710-712$.

8. Yamashita, M.; Fenn, J. B. J. Phys. Chem. 1984, 88, 4671-4675.

9. Aleksandrov, M. L.; Besuklandnikov, P. V.; Grachev, M. A.; Elyakova, L. A.; Zyyaginsteva, T. N.; Kondratsev, V. M.; Kusner, Yu. S.; Mirgorodskaya, 0. A.; Fridlyansky, G. V. Bioorg. Kim 1986, 12, 1689-1692.

10. Aleksandrov, M. L.; Barama, G. I.; Gall, L. N.; Krasnov, N. V.; Kusner, Yu. S.; Mirgorodskaya, 0. A.; Nikolaev, V. I.; Shkurov, V. A. Bioorg. Kim 1985, 11, 700-705.

11. Aleksandrov, M. L.; Baram, G. I.; Gall, L. H.; Grachev, M. A.; Knorre, V. D.; Krasnov, N. V.; Kusner, Yu. S.; Mirgorodskaya, O. A.; Nikolaev, V. I.; Shkurov, V. A. Bioorg. Kim 1985, 11, 705-708.

12. Whitehouse, C. M.; Dreyer, R. N.; Yamashita, M.; Fenn, J. B. Ana7. Chem. 1985, 57, 675679.

13. Aleksandrov, M. L.; Kondratsev, V. M.; Kusner, Yu. S.; Mirgorodskaya, 0. A.; 


\begin{tabular}{|c|c|c|c|c|}
\hline & & $\begin{array}{l}\text { JEPARTMENT OF ENE } \\
\text { and Field office }\end{array}$ & & Attachment \\
\hline & Field Hork Pr & 1 (Optional Cont & on Sheet) & Page 9 of 15 \\
\hline $\begin{array}{l}\text { Contractor Hame } \\
\text { Battelle Memorial Institute } \\
\text { Pacific Northwest Laboratory }\end{array}$ & Work Package No. & $\begin{array}{l}\text { Contractor No. } \\
20143\end{array}$ & Revision Mo. & $\begin{array}{l}\text { Date Prepared } \\
01 / 15 / 93\end{array}$ \\
\hline
\end{tabular}

Podtelezhnikov, A. V.; Fridlyanskü, G. V. Bioorg. Kim 1988, 14, 852-857.

14. Wong, S. F.; Meng, C. K.; Fenn, J. B. J. Phys. Chem. 1988, 92, 546-550.

15. Meng, C. K.; Mann, M.; Fenn, J. B. Z. Phys. D. 1988, 10, 361-368.

16. Loo, J. A.; Udseth, H. R.; Smith, R. D. Biomed. Environ. Mass Spectrom. 1988, 17, $411-$ 414.

17. Loo, J. A.; Udseth, H. R.; Smith, R. D. Rapid Commun. Mass Spectrom 1988, 2, 207-210.

18. Covey, T. R.; Bonner, R. F.; Shushan, B. I.; Henion, J. D. Rapid Commun. Mass. Spectrom. $1988,2,249-256$.

19. Smith, R. D.; Loo, J. A.; Rockwood, A. L.; Light, K. J.; Busman, M.; Winger, B. E. Mass Spectrom. Rev., manuscript in preparation.

20. Burlingame, A. L.; Baillie, T. A.; Russell, D. H. Anal. Chem. 1962, 64, 467R-502R.

21. Smith, R. D.; Barinaga, C. J.; Udseth, H. R. Ana7. Chem. 1988, 60, 1948-1952.

22. Vonnegut, B.; Neubauer, L., J. Colloid, Sci. 1952, 7, 616-622.

23. Smith, D. P. H. IEEE Trans. Ind. App7. 1986, 1A-22, 547-535.

24. Chowdhury, S. K.; Chait, B. T. Ana7. Chem. 1991, 63, 1661-1664.

25. Ikonomou, M. G.; Blades, A. T.; Kebarle, P. Ana7. Chem. 1991, 63, 1989-1998.

26. Vesta7, M. L.; A7len, M. H. Proceedings of the 39th ASMS Conference on Mass Spectrometry and Alijed Topics, Nashville, TN. 1991, pp 445-446.

27. Fernandez de la Mora, J.; Rosell-Llompart, J. Proceedings of the 39th ASMS Conference on Mass Spectrometry and Allied Topics, Nashville, TN, 1991, pp 441-442.

28. A17en, M; Lewis, I.A.S. US Patent 4,999,493, 1991.

29. Lee, E. D; Henion, J. D. Proceedings of the 36th ASMS Conference on Mass Spectrometry and A11 ied Topics, San Francisco, CA, 1988, pp 1308-1309.

30. Fenn, J. B.; Mann, M.; Meng, C. K.; Wong, S. F.; Whitehouse, C. M. Mass Spectrom. Rev. $1990,9,37-70$.

32. Kelly, A. J. J. Appl. Phys. 1976, 47, 5264-5271.

33. Iribarne, J. V.; Thomson, B. A. J. Chem. Phys. 1976, 64, 2287-2284.

34. Thomson, B. A.; Iribarne, J. V. J. Chem. Phys. 1979, 71, 4451-5563.

31. Taf7in, D. C.; Ward, T. L.; Davis, E. J. Langmuir 1989, 5, 376-384.

35. Chowdhury, S.K.; Katta, V.; Chait, B. T. Rapid Commun. Hass Spectrom. 1990, 4, 81-87.

36. Ogorzalek Loo, R. R.; Udseth, H. R.; Loo, J. A.; Smith, R. D.; Proceedings of the 38th ASMS Conference on Mass Spectrom and ATlied Topics, Tucson, AZ, 1990, pp 142-143.

37. Rockwood, A. L.; Busman, M.; Smith, R. D. J. Phys. Chem., submitted.

\section{Approach}

This project will utilize a combination of high level computational fluid dynamics and measurements of ion optics related phenomena to develop greatly improved electrospray ion sources for mass spectrometers. Our approach is dictated by the belief that an empirically driven approach to improving ESI source designs will be slow, expensive, and largely impractica7. The reason that ESI source design has been largely empirical arises from the complexity of predicting ion motion in regions where gas pressure is changing rapidly and ion-ion repulsive interactions are strong. Thus, most ESI sources constructed to date have been either (a) developed based upon ion optics in which collisional and space charge processes are neglected (i.e., in vacuum), or (b) have been straight forwardly adapted from beam dynamics techniques developed to sample unperturbed neutral (i.e., uncharged beam components). In the first case (a), it is clear that this approach is inappropriate. The collision rate is far too great in the expansion region for trajectory calculations to be of use. In the second case, the beam dynamics techniques (generally involving a series of 


\begin{tabular}{|c|c|c|c|c|}
\hline & \multicolumn{3}{|c|}{$\begin{array}{l}\text { U. S. DEPARTMENT OF ENERGY } \\
\text { Richland Field office }\end{array}$} & Attachment \\
\hline & \multicolumn{3}{|c|}{ Field Mork Proposal (Optional Continuation Sheet) } & Page 10 of 15 \\
\hline Contractor Name & Nork Package No. & Contractor No. & Revision No. & Date Prepared \\
\hline $\begin{array}{l}\text { Battelle Memorial Institute } \\
\text { Pacific Northwest Laboratory }\end{array}$ & & 20143 & & $01 / 15 / 93$ \\
\hline
\end{tabular}

precisely aligned beam skimmers) impose substantial design constraints and are demonstrably inefficient. The concerns for ion sampling and neutral sampling are much different, due to the ability to affect ion motion with electric and magnetic fields, and such designs are then only starting points toward an optimum design. Experimental optimization of such designs is an extremely expensive undertaking, and is largely impractical. The starting point for the optimization process may impose design constraints that could prevent the necessary level of improvement being obtained.

Our computational approach will be to start from a fluid dynamic continuum model and develop the code to include an ion source and to examine the expansion region. This approach makes maximum use of the experience developed here at PNL. The starting point for this development will be the Computational Fluid Dynamics code, TEMPEST, developed at PNL. TEMPEST solves the three-dimensional, time dependent equations governing turbulent (or laminar) heat, mass, and momentum transport. It has a state of the art turbulence model, and an electric field solution that can readily be modified for this application. The code is adaptable to any generalized orthoganol coordinate system and accepts geometries and boundary conditions as inputs.

The electrospray will be modeled by calculating the trajectories of an appropriate collection of source particles using a Lagrangian formulation of the equations of motion. This formulation allows a distribution of "source" particle sizes, charges, positions, and velocities. It also provides for particle characteristics to change by liquid evaporation, Rayleigh fission, or other means. The trajectories will be used to solve for the local electric fields. These particle motion and electrostatic equations are coupled to themselves and to the fluid dynamic conservation of mass and conservation of momentum equations. This set of coupled equations, along with the appropriate constitutive relations, will be solved using a time marching approach, where the equations are solved sequentially during a time step. Code modifications will be required to compute the fluid dynamics at very low pressures as well as standard pressures.

This code will provide a powerful and flexible approach for the evaluation of source design concepts, especially those which differ radically from the conventional nozzle-skimmer concepts borrowed from beam dynamics work. It is expected that this model will provide insight into the complex interactions of gas dynamics and electrostatics on the motion of charged particles as they pass from atmospheric pressure into the mass spectrometer. It will permit the examination of "close" geometries which minimize the distance the ions have to travel, and thereby allow consideration of designs which reduce space charge effects vs. more extended geometries where additional electrostatic elements are used to try to refocus the ion signal. It will permit the evaluation of fringing field effects and shock wave disruption of ions for geometries that do not utilize skimmed molecular beams.

In conjunction with computational methods, experimental studies will contribute by providing selected experimental measurements necessary for ion trajectory simulations and for evaluation of prototype ion source designs based upon the computational studies. The experimental studies will be used to evaluate the computer simulations. For example, they will be used to cross-check computational predictions of gas flows, and electric (and possibly magnetic) fields upon source performance. These studies should serve to illuminate any deficiencies in the computation methods (i.e., in the assumptions and approximations necessarily invoked to make them tractable). The ion sources will initially be evaluated on 
Field Work Proposal (Optional Continuation Sheet)

a test stand (without mass spectrometry) to determine beam quality and intensity. The source will then be transferred to a quadrupole mass spectrometer at PNL to confirm the above predictions, and to evaluate other ion beam qualities (particularly ion desolvation). The overall quality of the source will depend upon its (a) useful beam intensity, (b) translational energy distribution, (c) collimation, (d) stability, and (e) ion desolvation. In addition, the flexibility to control the internal activation of molecular ions over a broad $\mathrm{m} / \mathrm{z}$ range as well as a broad range of molecular weights is important, so that dissociation of molecular ions can be accomplished in the interface to provide structural information. It is important that the Tatter be accomplished efficiently without significantly degrading source performance.

The third major component of this project will primarily be conducted by Finnigan MAT researchers in conjunction with PNL staff. PNL will develop prototype ion source designs based upon mass spectrometer design considerations supplied by Finnigan MAT. Finnigan MAT researchers will then construct ion sources optimized for specific instruments. Finnigan MAT researchers will provide information on the results of these studies, and participate in any further source optimization steps. Finnigan. MAT will also assist PNL in source design efforts by providing any source and interface elements necessary for PNL prototype development, and will assist PNL with their extensive experience in mass spectrometer design and the interfacing of other ion sources to mass spectrometers. The result of this project is anticipated to provide Finnigan MAT with the basis for a greatly improved and more sensitive ESI source for their MS instrument line, and initial prototype designs for their evaluation.

\section{Technical Progress}

\section{FY 1993}

This is a new project to be initiated in FY 1993. Publications describing previous PNL research with electrospray ionization are given in Section J. The emphas is in FY 1993 will be to (1) modify the computational fluid dynamics computer code to incorporate features necessary to simulate ESI. conditions, (2) conduct experimental studies investigating ion transport at various gas pressures, in capillaries, and in electric or magnetic fields as a function of ion density. The study of ion density affects is important since it will allow evaluation of our success in modifying the fluid dynamics code to adequately account for ionion repulsive interactions.

Task 1 Modification of Fluid Dynamics Computer Code. PNL's fluid dynamics program will be modified to incorporate changes necessary for charged particles. This will include incorporation of long range ion-ion repulsive interactions (i.e., space charge effects). The code will be modified so that various physical structures can be incorporated to simulate an actual ESI source and interface region, and to allow adjustment of gas hydrodynamics in the various pressure regimes (including bulk gas flows), and the imposition of both electric and magnetic fields.

Task 2 Experimental Measurements of Ion Focusing Phenomena. Experimental studies will be conducted at various ion densities relevant to ESI source design to evaluate beam focusing properties in external and magnetic fields. The use of gas hydrodynamic forces to enhance ion transport will be evaluated. These results will be used to evaluate initial fluid 
dynamics simulations to determine the adequacy of the methods. In addition, ion mobility data will be obtained for a fely typical compounds at different stages of desolvation to allow a more realistic evaluation of ion solvation effects upon ion source operation. These studies will be conducted using existing vacuum equipment and ion mobility and mass spectrometric instrumentation at PNL.

The studies in FY 1993 will involve interaction of Dr, A. L. Rockwood of PNL's Chemical Sciences Department, and a post-doctoral associate (J. E. Bruce) with D. S. Trent and D. L. Lessor (Computer Sciences Department), who will modify and evaluate PNL's Fluid Dynamics Code. Dr. H. R. Udseth, with J. E. Bruce, will conduct the experimental studies. Dr. R. D. Smith will be the Project Manager and will maintain a high level of interaction with Finnigan MAT to assure that the results of their studies are incorporated at PNL. A1though of 1 imited importance in FY 1993, Dr. C. G. Edmonds will interact at both Finnigan MAT and PNL to evaluate ESI-MS instrumentation with selected applications. In addition, visits by Finnigan MAT researchers under the guidance of Dr. Ian Jardine will assist in transfer of technology.

\section{FY 1994}

During FY 1994, the major emphasis of this project will be the application and further refinement of the fluid dynamics code for ESI source simulation. In addition, initial ion source designs arising from the simulation studies will be evaluated experimentally.

ESI Source Simulations. The computer simulation methods will first be evaluated by conducting simulations of existing ESI sources at PNL. At least four different ESI source designs are currently available at PNL. Any substantial discrepancy will require additional modification of our computational methods. After satisfactory agreement with experiments is obtained for existing sources, new ESI source configurations will be evaluated. Initial emphasis will be placed on designs suggested on the basis of previous PNL experience, and will incorporate guidance from Finnigan MAT based upon their in-house studies. Various combinations of electric, magnetic, fields and hydrodynamic flow will be evaluated.

ESI Source Evaluation. Based upon the above results, new prototype ESI sources will be constructed using existing PNL resources. Test measurements will be made to determine ion beam quality and the nature of any ion losses in the interface. The results will be used to provide guidance for additional modifications prior to transfer to a mass spectrometer, or for further modification to the simulation methods.

ESI-MS Performance Measurements. The ESI source will be evaluated to determine ion desolvation efficiency, and performance under conditions requiring various levels of ion activation. The aim of these studies will be to demonstrate overall increase in sensitivity of $10^{2}$ to $10^{3}$, and an overall efficiency of more than $10 \%$.

\section{FY 1995}

The precise nature of the research in FY 1995 will depend strongly on progress in earlier years. We anticipate that the major emphasis during FY 1995 will involve the interaction with Finnigan MAT researches to develop ESI sources based upon the prototype designs evaluated in FY 1994. The computer simulation methods will be used to optimize the selected source design(s) for Finnigan MAT mass spectrometers. In parallel with these efforts, the ion 
source design and refinement will continue and attractive elements will be adopted in our prototyping efforts as feasible. Finnigan MAT researchers will visit PNL during this time to assist in the technology transfer as necessary to implement the new ESI source designs at Finnigan MAT. Where not impacting Finnigan MAT proprietary information, the results of the simulation studies will be published in peer-reviewed scientific literature. PNL researchers will also assist in evaluation of the new ion source technology by investigating a range of applications which are presently precluded due to sensitivity limitations. These results will also be published in the open literature.

\section{E. Facility Requirements}

The PNL facilities used in this research include the mass spectrometry laboratories in 326 Building and PSL. A wide range of measurement instrumentation, vacuum test stands, and four mass spectrometers currently equipped with electrospray ionization sources are avajlable at PNL. Machine and electronic shops are also available to assist with ESI source development. The Computer Sciences Department at PNL has developed the fluid dynamics programs to be used on this project, and will assist with their modification.

\section{F. Future Accomplishments}

This project will provide the basis for greatly improved analytical techniques of relevance to a wide range of applications which include environmental analyses, waste monitoring, clinical assays, etc. The primary direct impact of this project will be an enhanced competitiveness of U.S. industry in the crucially important area of analytical measurement technology. A wide range of secondary benefits will accrue from application of this technology.

\section{G. Relationship to Other Projects}

This project is aimed at the study of ion transport processes and their utilization in development of great7y improved ESI-MS analytical instrumentation. This project derives, and direct7y benefits, from other projects in the Chemical Sciences Department at PNL developing advanced mass spectrometric instrumentation. The OHER supported project, "Development of Capi17ary Electrophoresis-Mass Spectrometry for DNA Adducts," has directly supported electrospray ion source development at PNL as a mechanism for interfacing capillary electrophoresis and MS. The sensitivity gain provided by this project would also benefit the on-going OHER project, and greatly increase the applicability of these methods in DNA adduct and damage research at PNL. A second project at PNL, also supported by OHER, under the Human Genome project, is aimed at developing new DNA sequencing methods based upon ESI and MS. This project would also benefit from the proposed project. R. D. Smith is Principal Investigator in the above projects, with Drs. H. R. Udseth, A. L. Rockwood, and C. G. Edmonds as key contributors.

In addition to these projects, the new Environmental and Molecular Sciences Laboratory (EMSL) under development at PNL includes a major role for advanced instrumentation utilizing electrospray ionization. As with the other projects noted above, this project will benefit from the proposed effort. 


\section{H. Environmental Assessment}

Preliminary NEPA review suggest that this proposal will meet the criteria for the Laboratory Benchscale Memorandum-to-Fjle. Required documentation will be prepared prior to project initiation.

\section{Explanation of Milestones}

Milestones for FY 1993 are set forth below.

Task 1. The fluid dynamics code will be modified to account for ion-ion repulsive processes to allow simulation of ESI source designs.

Task 2. Experimental measurements of ion mobility will be conducted at various ion densities and at various stages of ion desolvation.

Task 3. Initial ESI source simulations will be conducted.

\section{J. Publications}

Listed below are a few selected publications from the more than 60 peer-reviewed publications from PNL involving electrospray ionization. In addition to PNL's experience and expertise in ESI source development, PNL has been awarded two patents and an R\&D 100 Award for development of an electrospray ionization interface for combined capillary electrophoresis-mass spectrometry.

01 ivares, J. A., Nguyen, N. T., Yonker, C. R., and Smith, R. D., 1987 "On-1ine Mass Spectrometric Detection for Capillary Zone Electrophoresis." Anal. Chem. 59;1230-1232

Smith, R. D., 01ivares, J. A., Nguyen, N. T., and Udseth, H. R., 1988 "Capillary Zone Electrophoresis -Mass Spectrometry Using an Electrospray Ionization Interface." Anal. Chem. $60 ; 436-441$

Loo, J. A., Udseth, H. R., and Smith, R. D., 1988 "Collisional Effects on the Charge Distribution of Large Molecules from Electrospray Ionization-Mass Spectrometry," Rapid Commun. Hass Spectrom. 2;207-210

Loo, J. A., Udseth, H. R., and Smith, R. D., 1988 "Solvent Effects on the Charge Distribution Observed with Electrospray Ionization-Mass Spectrometry of Large Molecules, "Biomed. Environ. Mass Spectrom, 17;411-414

Loo, J. A., Udseth, H. R., and Smith, R. D., 1989 "Peptide and Protein Analysis by Electrospray Ionization-Mass Spectrometry and Capillary Electrophoresis-Mass spectrometry," Anal. Biochem, 179;404-412

Loo, J. A., Edmonds, C. G., and Smith, R. D., 1990 "Primary Sequence Information from Electrospray Ionization Tandem Mass Spectrometry of Intact Proteins," Science 248;201-204

Smith, R. D., Barinaga, C. J., and Udseth, H. R., 1988 "Improved Electrospray Ionization Interface for Capillary Zone Electrophoresis-Mass spectrometry, "Ana1. Chem. 60;1948-1952 
Smith, R. D., Loo, J. A., Edmonds, C. G., Barinaga, C. J., and Udseth, H. R., 1990 "New Developments in Biochemical Mass Spectrometry: Electrospray Ionization", Anal. Chem. 62;882899

Smith, R. D., Loo, J. A., Edmonds, C. G., Barinaga, C. J., and Udseth, H. R., 1990 "Sensitivity Considerations for Large Molecule Detection by Capillary ElectrophoresisElectrospray Ionization Mass Spectrometry," J. Chromatography 516;157-165

Chapman, E. G., Barinaga, C. J., Udseth, H. R., and Smith, R. D., 1990 "Confirmation and Quantitation of Hydroxymethanesulfonate in Precipitation by Electrospray Ionization-Tandem Mass Spectrometry," Atmospheric Environment 24A;2951-2957

Loo, J. A., Edmonds, C. G., and Smith, R. D., 1991 "Tandem Mass Spectrometry of Very Large Molecules: Serum Albumin Sequence Information from Multiply Charged Ions formed by Electrospray Ionization," Anal. Chem. 63;2488-2499

Rockwood, A. L., Busman, M., and Smith, R. D., 1991 "Thermally Induced Dissociation of Ions in Electrospray Mass Spectrometry," Rapid Commun. Mass Spectrom. 5; 582-585

Loo, J. A., Ogorzalek Loo, R. R., Light, K .J., Edmonds, C. G., and Smith, R. D., 1992 "Multiply Charged Negative Ions by Electrospray Ionization from Polypeptides and Proteins," Ana1. Chem. 64;81-88

Busman, M., Rockwood, A. L., and Smith, R. D., 1992 "Activation Energies for Gas Phase Dissociations of Multiply Charged Ions from Electrospray Ionization Mass Spectrometry," J. Phys. Chem. 96;2397-2400

Smith, R. D., Loo, J. A., Ogorzalek Loo, R. R., Busman, M., and Udseth, H. R., 1991 "Principles and Practice of Electrospray Ionization-Mass Spectrometry for Large Polypeptides and Proteins," Mass Spectrom. Rev. 10;359-451

Loo, J. A., Ogorzalek-L00, R. R., Udseth, H. R., Edmonds, C. G., Smith, R. D., 1991 "SolventInduced Conformational Changes of Polypeptides Probed by Electrospray Ionization-Mass Spectrometry," Rapid Commun. Mass Spectrom. 5;101-105

Smith, R. D., Light-Waht, K. J., Winger, B. E., and Loo, J. A., 1992 "Preservation of Noncovalent Association in Electrospray Ionization-Mass Spectrometry: Formation and Dissociation of Multiply Charged Polypeptide and Protein Dimers, " Org. Mass Spectrom. 27;811821.

Ogorzalek Loo, R.R., Udseth, H. R., and Smith, R. D., 1992 "A New Approach for the Study of Gas phase Ion-Ion Reactions using Electrospray Ionization," J. Amer. Soc. Mass Spectrom. press. 


\section{Distribution}

No. of

Copies

OFFSITE

2 DOE/Office of Scientific and

Technical Information

M. Abbot

Laboratory Management Division

U.S. Department of Energy

Office of Energy Research

Forrestal Building (ER-42)

1000 Independence Avenue, SW

Washington, DC 20585

T. Vojnovich

Technical Program Manager

ER Laboratory Technology Transfer Program

U.S. Department of Energy

Forrestal Building (ST-311)

1000 Independence Avenue, SW

Washington, DC 20585

A. M. Zerega

Laboratory Management Division

U.S. Department of Energy

Office of Energy Research

Forrestal Building (ER-42)

1000 Independence Avenue, SW

Washington, DC 20585
No. of

Copies

ONSITE

DOE/Richland Field Office

G. McClure, A5-90

10 Pacific Northwest Laboratory

C. G. Edmonds

P8-19

M. Clement

K1-17

R. D. Smith

P8-19

B. J. Harrer

K1-12 Technical Report Files (5)

Distr. 1 